\title{
What We Talk About When We Talk About Design
}

\author{
Toward a Taxonomy of Design Competencies
}

\begin{abstract}
What is it that designers talk about as mattering in their professional competencies? In this article, we empirically investigated industrial designers' own assumptions on their design practice in relation to innovation. In applying a method potentially suitable for design research, interview statements from design professionals $(n=17)$ were categorised according to 12 pre-selected categories of potential design core competencies. Of a total of 2,267 statements, 1,990 were classified as related to design competence. A qualitative classification of the statements revealed that 1,259 (63.3\%) of these could be classified under the pre-set categories. The results showed that out of the 12 categories, 'creativity', 'particular design methods and techniques' and 'user' were emphasised. From the remaining statements, two additional categories were revealed: 'teamwork' and 'project management'. These results can be used to reveal design professionals' self-understanding of their contributions to innovation processes.
\end{abstract}

Keywords: design competence, taxonomy, innovation, industrial design

\section{Introduction}

\section{Design knowledge as diverse}

Over the last five decades, we have seen an emerging body of research on the nature of design, its processes and how designers work (Bayazit, 2004; Cross, 2007). The variety and richness of approaches and types of inquiry into design can be seen in several new books that survey modes of inquiry and means of design making and reflection (Crouch \& Pearce, 2012; Grand \& Jonas, 2012; Koskinen, 2011). At one level, research on industrial design has emphasised the more cognitive aspects of how designers work and think (Cross, 2006; Cross, Dorst, \& Christiaans, 1996; Dorst \& Cross, 2001; Lawson, 1997, 2004; Lawson \& Dorst, 2009). The design research community has also studied the practice of design and design methodology, which has led to the building of new knowledge (Cross, 1984). Within design research into such knowledge building, there has been an interest in viewing design practice as a social process. This has extended to studying the actual verbal interaction between designers during the design phase (McDonnell, 2012; McDonnell \& Lloyd, 2009; Oak, 2011). Broadly speaking, the approaches may be categorised as primarily cognitive or as socially situated, although some studies combine the two.

The components of design knowledge may be closely related to an understanding of two aspects: the purpose of design activity and the character of the type of assignments (or problems) that industrial designers are set to handle. Herbert Simon (1969) described design activity as devised courses of action aimed at changing existing situations to preferred ones. The character of design problems has been described as wicked (Buchanan, 1992; Rittel \& Webber, 1973), and the set of activities or the approach that designers seemed to adopt to solve these wicked problems have been typified as reflection in action (Schön, 1983).

Interestingly, design research seldom takes a knowledge theory approach to understand design knowledge and related processes better (Argyris \& Schön, 1974; Hatchuel \& Weil, 1995; Hubka \& Eder, 1990). In this article, we draw on aspects of approaches to design knowledge to explore how industrial design professionals typify their own competencies. We draw on such approaches to reveal how industrial designers' own 
characterisations may help us enrich the understanding of how they work creatively and productively in the context of professional work.

\section{The design 'conversation'}

The title of this article is inspired by the novel What I Talk About When I Talk About Running by the Japanese writer Haruki Murakami. In his novel, Murakami presents information and knowledge about running from his first-hand perspective as an experienced runner. In our study, we asked industrial designers about their own approaches and assumptions concerning their professional practices. We were keen to examine more closely how designers perceive and talk about their own design practices, processes and knowledge. The metaphor of talk has been widely circulated in design research. The earlier work of Donald Schön, such as The Reflective Practitioner (1983), emphasised that designers engage in 'conversations with materials'. These conversations are concerned with designers coming to know the properties and character of the materials in use. However, these materials also 'talk back' in the processes of design; they are part of the dialogue of designing.

In our study, we engaged in dialogue in several ways. First, by adopting an experimental method for generating empirical data based on qualitative interviews, our aim was to let the industrial design professionals 'talk' more freely about their approaches to design and innovation. This method has been successfully adopted in other research fields (Lone et al. 2013). Second, by inviting industrial designers to talk about their work and expertise, we wanted to identify what they talk about most when talking about design. The method we adopted gave the industrial designers (the informants) an opportunity to reflect freely on their relationship with and understanding of innovation and their design competence. Third, we subsequently counted and measured how often the different topics were mentioned, thereby providing a substantial meta mapping of separate conversations. Fourth, this resulted in an empirical data set that rated the focus on a series of different categories that describe design core competencies. Fifth, taken together, this mix of methods, discourses and analyses - a wider and multi-level 'conversation' between contexts, person and information-allowed us to look more substantially into links between qualitative and quantitative accounts of the work processes and professional knowledge of industrial designers. Finally, one key area that stood out in the study is the category of teams and their work practices. A high number of statements concerned team- and teamwork-related issues. This shows that understanding design competencies entails an appreciation of situated social sense, since design knowledge is created through collaboration and shared inquiry.

\section{Overview and approach}

In this study, our general aim was to develop and refine a list of categories that can offer some insight into the self-articulated design competencies of professional industrial designers. This was approached through open-ended interviews that were connected to a set of categories we devised and then later revised. In the next section, we situate this approach by referring to literature on design knowledge. We then present the methods adopted in more detail. Next, we outline the study results, discuss the results in detail and offer a short conclusion.

The designers we consulted were located in one Nordic country, Norway, where industrial design has established and influential traditions and is known for its expertise and products. Our research design was interdisciplinary from the outset, drawing on both design and competencies from the team's own expertise in industrial design, psychology, interaction design and innovation. Having identified the core research issues to be pursued, to be able to score statements with the experimental method, we adopted a set of reference categories influenced by techniques common in research in psychology. This meant that we needed a list 
of categories and descriptors of design core competencies; these also needed to be independent from the statements in the interviews that would follow. We drew up the categories and conducted the interviews in dialogue with one another as researchers and designers taking part in a funded research project group.

Overall, this approach drew in part from principles of grounded theory (Glaser \& Strauss, 1967; Strauss \& Corbin, 1990, 1997). However, we aligned our approach with more recent critiques of the uncritical application of the terms 'grounded' and 'theory', such as the one by Thomas and James (2006, p. 790), who stated,

grounded theory elevates a certain kind of thinking while it demotes and eschews other kinds of thinking and understanding. In its hankering after order — with its fracturing, its axial coding, its categories and sub-categories - it seeks to impose a certain kind of patterning, shape, and even rationality. Via such procedures it thereby relegates the original voice - the narrative - of both the respondent and the discussant in the research exercise. By the superimposition of method, and the ultimate production, supposedly, of theory, it implies a dismissal of the direct validity and import of people's accounts, such as those children who fail to adapt to the school system or fail to learn in that system.

In referring to designers' own reflective accounts of their expertise and ways of working, we have sought to reflect on how knowledge is built in dynamic processes of development and contextualisation. However, we have been keen careful to also see these accounts as more than merely subjective descriptions.

We first discussed different terms that can constitute design competence. In doing so, we referred to our own situated experience, both as designers and researchers, together with insights garnered from published research. Based on the discussions and research, a set of 12 categories describing design issues about design knowledge was generated. Second, a series of open-ended interviews with a selection of industrial design professionals was carried out. Informants were invited to reflect upon their own work practices and understanding of innovation. Their responses were then classified under the given categories and analysed with statistical methods. The results of this mapping allowed us to reassess the given categories and to identify the need for two additional ones.

In the latter part of the article, these results are discussed in terms of their implications for better contributions to the contexts of design work and education. We suggest that the two categories we identified following the interviews and coding may have a useful bearing on design education and the development of a more informed, dynamic view of knowledge in design. To contextualise the background of the study, some of the core literature on design knowledge is reviewed in the next section.

\section{Review}

\section{Describing core design competencies}

Several attempts to describe the designers' competencies appear in the research literature. According to Nelson and Stolterman (2003), the ability or competence to come up with an idea and to give form, structure and function to that idea is at the core of design as a human activity. Nigel Cross (2006, p. 12) summarised design knowledge (ability) as 'the comprising abilities of resolving ill-defined problems, adopting solution-focused cognitive strategies, employing abductive reasoning or appositional thinking and using non-verbal modelling media'. Design core competencies are also described simply as 'creativity', 'helping others innovate' and 'the ability to draw' (Conley, 2004, p. 1). 
Most of the work mentioned above examined the cognitive aspects of design competencies, which, according to Cross (2006, p. 13), may be grouped as 'the formulation of problems, the generation of solutions, and the utilisation of design process strategies'. Another perspective, however, concerns the social aspects of the design competencies. Social aspects have gained attention with the increased focus on exploring digital design (Wagner, Stuedahl, \& Bratteteig, 2010), and with interaction elements and interaction design knowledge (Löwgren \& Stolterman, 2004; Moggridge \& Atkinson, 2007; Redström, 2006) also influencing traditional industrial design. This opens up completely new fields of research. For instance, Bruno Latour (2005), with the Actor-Network-Theory, has inspired us to look upon design and interactions in completely different and negotiative ways, gathered around concepts such as assembly. The implication of these developments is that earlier, more historical conceptions of design competence, partly associated with the drive to read and constitute design as a science, have been conceived of as developmental, situated and dynamic modes of making and knowing.

In this regard, researchers have recently described design competencies that are based on design skills and knowledge in terms of design thinking. According to Tim Brown (2009), design thinking relies on our ability to be intuitive, to recognise patterns, to construct ideas that have emotional meanings as well as functionality and to express ourselves in media other than words or symbols. Lucy Kimbell (2011) stated that the background of the concept has to do with the ways that professional designers solve problems and how this is of value to firms trying to innovate. The use of the term has accelerated discussions on how to treat the subject of design knowledge, bringing in another dimension to the already complex landscape of research on design knowledge. Thomas Lockwood (2010) sees design thinking not as a substitute for professional design but as a methodology for innovation. He describes design thinking as a human-centred innovation process that emphasises observation, collaboration, fast learning, visualisation of ideas, rapid concept prototyping and concurrent business analysis, where the objective is to involve consumers, designers and business people in an integrative process that can be applied to product, service or even business design.

The propositions of Lockwood and Kimbell concern the extent to which the design professional should be considered a generalist or a specialist. Generalist thinking is directed toward investigating the social aspects of design processes; specialist thinking is directed more toward investigating the cognitive aspects of design competencies. More attention to generalist thinking may result in a focus on the designer as the social facilitator of design and product development processes. In our view, the industrial designer often appears as the combination of both aspects, and competencies are a complex mix and negotiation situated in contexts, materials and tools, yet also linked with applied cognitive abilities and approaches.

One instance where the term competencies is used explicitly in the domain of design is in Chris Conley's (2004) research on skills and knowledge. Conley (2004, p.2) classified design skills and knowledge according to the following set of competencies:

1. The ability to understand the context or circumstances of a design problem and frame them in an insightful way

2. The ability to work at a level of abstraction appropriate to the situation at hand

3. The ability to model and visualize solutions even with imperfect information

4. An approach to problem solving that involves the simultaneous creation and evaluation of multiple alternatives

5. The ability to add or maintain value as pieces are integrated into a whole

6. The ability to establish purposeful relationships among elements of a solution and its context, and

7. The ability to use form to embody ideas and to communicate their value. 
According to Conley, none of the examples are directly empirically informed, meaning they are strictly descriptive and do not refer to what designers actually do or say they do. These examples are 'based only on reflection of design practice over the past 15 years' (Conley, 2011, p. 1).

Attempts to scrutinise design competence have become either very general or overly detailed. The attempts overlap with the ontological and epistemological requirements and framing of other disciplines and provide limited insight into why a designer adds this kind of value to his or her activity and outcomes (Conley, 2004). Conley (2011, p. 1) goes on to argue that common assumptions of relevant core design competencies

do not seem to capture the essence of what designers really do. Some of them are far too general, like 'creativity.' All disciplines require creativity — design does not hold a disciplinary right to it. Other suggestions are often skill based, like 'the ability to draw.' Certainly designers need this skill, but drawing itself does not constitute design competence.

In our study, as a response to generate design knowledge with these typically interpretative activities in mind, we adopted an experimental method taken from psychology. This method gives us some empirically informed material that moves the discourse into more tangible domains, in conjunction with semi-structured interviews with individual designers.

In this article, we therefore propose and test a method by focusing on the categories or 'building blocks' that may be used to describe design core competencies. We incorporate general categories (such as creativity) and more specific skills (such as drawing, in this case under the label 'visualisation'). Finally, we assume that no list can effectively capture all variants of design competencies. Instead, we see such a specification partly as a moving target where the content and the proportions of different competencies change over time between individual designers and different projects; this may be taken up in later studies.

\section{Research Design and Methods \\ Devising a set of categories}

Separate from the interviews, we established a list of relevant categories that describe design core competencies. The list was not empirically informed but was based on more than 25 years of both professional and academic experience in industrial design between the authors, reviews of design theory and surveys of the curricula of several design programmes around the world. The initial list included 12 categories: holistic design approaches and methods, particular design methods and techniques, visualisation, aesthetics, use, user, context, technology, market, ecology, functionality and creativity. The details of these categories are as follows:

1) Holistic design approaches and methods. Holistic design approaches and methods refer to a professional designer's focus on a consistent picture of all elements related to or included in a product, rather than a focus on particular elements of a product. The term 'holistic' is characterised by the belief that the parts of something are intimately interconnected and explicable only by referring to the whole. This given system cannot be determined or explained by its components and parts alone. The term 'methods' refers to a certain procedure, especially a systematic or established one, for accomplishing or approaching something. Hence, in this case, it refers to methods that facilitate holistic approaches.

2) Particular design approaches and methods. Particular design approaches refer to the product designer's bias in primarily focusing on a few specific and specialised design methods and techniques. These can range from a single, quite narrow method to several single methods 
applied isolated in a sequence. Arguably, 'particular' can be understood in contrast to the concept 'holistic', i.e., approaches are either more or less holistic or more or less particular.

3) Visualisation. Visualisation refers to how designers visualise ideas and concepts through different media. This competence is essential in design professions for creating ideas and communicating. Visualisations may appear in a range of forms and media, such as diagrams, mood boards, sketches, videos, physical models and computer-aided models.

4) Aesthetics. Aesthetics covers situations that the designer relates to a product's aesthetic categories. Aesthetics is seen as a set of principles concerned with the nature and appreciation of beauty.

5) Use. Use includes activities where the designer considers the aspects of use and usability in the design work. The term 'use' refers to how the users of a product or service interact with or consume the object of concern.

6) User. User refers to how the designer interacts with and includes users in developing a design solution. The user can be described as a subject who uses or operates something.

7) Context. Context refers to the designer's way of reflecting upon the surroundings of an idea or an object. Context refers to the circumstances around a product or service that form the setting for an object where it can be fully understood. Nelson and Stolterman (2003) stated that context, for designers, consists of things that have been selected to stay unchanged in the face of a design change.

8) Technology. In this setting, technology covers the extent to which the designer is concerned with technological aspects at play. Technology can be seen as the use and knowledge of tools or systems. Technology is also the application of scientific knowledge for practical use, or applied science. The former is common among social scientists, while the latter is prominent among scientists and engineers.

9) Market. Market refers to the extent to which the designer considers market aspects during the design process. The aspect can be present in guidelines for developing a product and communicating with marketing professionals as stakeholders in the project.

10) Ecology. Ecology refers to the designer's concern about sustainability in developing a design and product.

11) Functionality. Functionality deals with how concerned the designer is with functional aspects. Functionality can be closely linked to the use and user aspects on one side and technology on the other.

12) Creativity. The term creativity refers to the extent to which the designer is concerned about being creative in the work, i.e., thinking in ways and developing concepts that are less traditional or even unexpected.

\section{Selected participants}

The informants, who are all industrial design professionals, were selected from a pool of industrial design graduates from the two leading sites of design education in Norway: the Oslo School of Architecture and Design and the Norwegian University of Science and Technology. The participants included 17 professional designers (five women and 12 men). The informants were selected from lists without further criteria, e.g., professional reputation, although individuals were excluded if they, at that time, worked within areas clearly distant 
from normal industrial design practice. Five of the selected designers had more than six years of professional experience, and 12 had less than six years of professional experience. All participants read and signed an informed consent form. They were not paid for their participation.

\section{On interviewing}

The primary aim of the adopted method was to generate a 'conversation' rather than ask formal directed questions in research interviews. As means to such conversations, in which we took part as designer-researchers, open-ended interviews were carried out. However, to structure interviews, a SWOT analysis format was employed. In a SWOT analysis, elements of concern are placed in one of four categories: strengths, weaknesses, opportunities or threats. In this study, the idea was to prompt the participant to reflect freely along two dimensions (positive vs. negative and the present vs. the future). The introductory question was designed as a 'warm-up' phase, and the SWOT questions followed thereafter.

The introductory question was 'How would you describe your approach as a designer in actual product innovations?' The four subsequent questions were 'What are the [strengths] [weaknesses] [opportunities] [threats] related to your approach as a designer in concrete product innovations?' Additional information was obtained by encouraging the informants to respond to supplementary questions such as the following:

'You have mentioned some strengths. Are there other strengths related to ...?'

'Did I get you right when you say that ...?'

'Could you illustrate this by giving an example?'

'Could you specify what you mean by ...?'

A few days beforehand, the respondents were given written information about the purpose and format of the interview, including the questions. The designers were asked for permission to tape record the interviews and were informed that the tapes would be erased after the content had been transcribed and categorised.

\section{Transcribing and coding}

The aim of transcribing is to obtain an accurate sense of the information provided, to present the informant respectfully and to ensure readability. A dilemma within the social sciences is how to make the interview conversation whole (Kvale \& Brinkmann, 2009) and emphasise the essence of context over exact phrases (Flick, 2009). As a result, the transcriptions were based on the informants' phrases, and as far as possible were true to the informants' articulations. Where direct transcriptions did not make sense, edits were made for greater clarity. When the recordings were transcribed, information such as the interviewees' names and positions and their organisation's name and exact location were deleted to ensure confidentiality. Eight randomly chosen interviews were subjected to a qualitative inter-rater reliability test. No significant discrepancies were detected.

Based on the transcriptions, specific statements were derived. Broadly speaking, a statement is a part of a sentence, a whole sentence or several sentences expressed by the interviewee that constitutes a coherent, meaningful point of view that describes an aspect of the design process. Identical statements were not coded twice, unless expressed by a different respondent, indicating an understanding across respondents. Similar statements were not coded twice unless they represented a further elaboration on an issue. 


\section{Coding of statements}

Every statement was coded based on whether or not it related to a competence in the list. Thereafter, statements classified as referring to a general competence were classified under a specific category in the list. In cases where the statement was classified as a general competence but did not fit into any of the specific categories, the statement was classified as a 'competence residual' (meaning the statement refers to a competence but not to any competence covered by the categories). Then, the content of the competence residual was analysed. The difference between the qualitative classification of statements and the content analysis of a residual is that the former involves classification into pre-specified categories, whereas the latter involves building new categories from the bottom up based on the content of the residual.

\section{Limitations}

The number of subjects we included in the study is insufficient to run inferential statistics. ${ }^{1}$ We did not test for differences between the experienced and the less experienced designers in the sample. ${ }^{2}$ Design competencies can be described at higher and more detailed levels. However, in this study, an abstraction level of around 12 to 15 dimensions is practical and probably useful for communicating about design. Furthermore, this abstraction level provides a solid qualitative base for creating quantitative questionnaires and assessment tools at a later point. Inter-rater reliability is an issue for this series of interviews. If different people score the data with different definitions in mind, the results can be flawed. ${ }^{3}$ Furthermore, the designers were recruited from two Norwegian universities with different approaches to design This might influence the data as well because there might be systematic differences between the two.

\section{Results}

This section presents the results that are based on the scoring of the 1,990 competence statements related to design practice under the 12 categories. The first part presents the results from the analysis. Following this, we reflect on the potential implications of these results with regard to four characteristics of industrial design professionals that we propose on the basis of the data analysis.

\section{The categories}

A total of 2,267 statements were derived from the interviews. Of these, 1,990 (87.8\%) were classified as a design competence. The categories accounted for 1,259 statements $(63.3 \%)$. In descending order, the distribution within the list was as follows (see Fig. 1): creativity, 249 statements (19.8\%); particular design methods and techniques, 182 statements (14.6\%); user, 155 statements (12.3\%); market, 141 statements (11.2\%); aesthetics, 98 statements $(7.8 \%)$; holistic design approaches and methods, 95 statements (7.5\%); visualisation, 79 statements (6.3\%); technology, 77 statements (6.1\%); functionality, 67 statements (5.3\%); use, 46 statements (3.7\%); context, 38 statements (3.0\%); and ecology, 32 statements $(2.5 \%)$. 


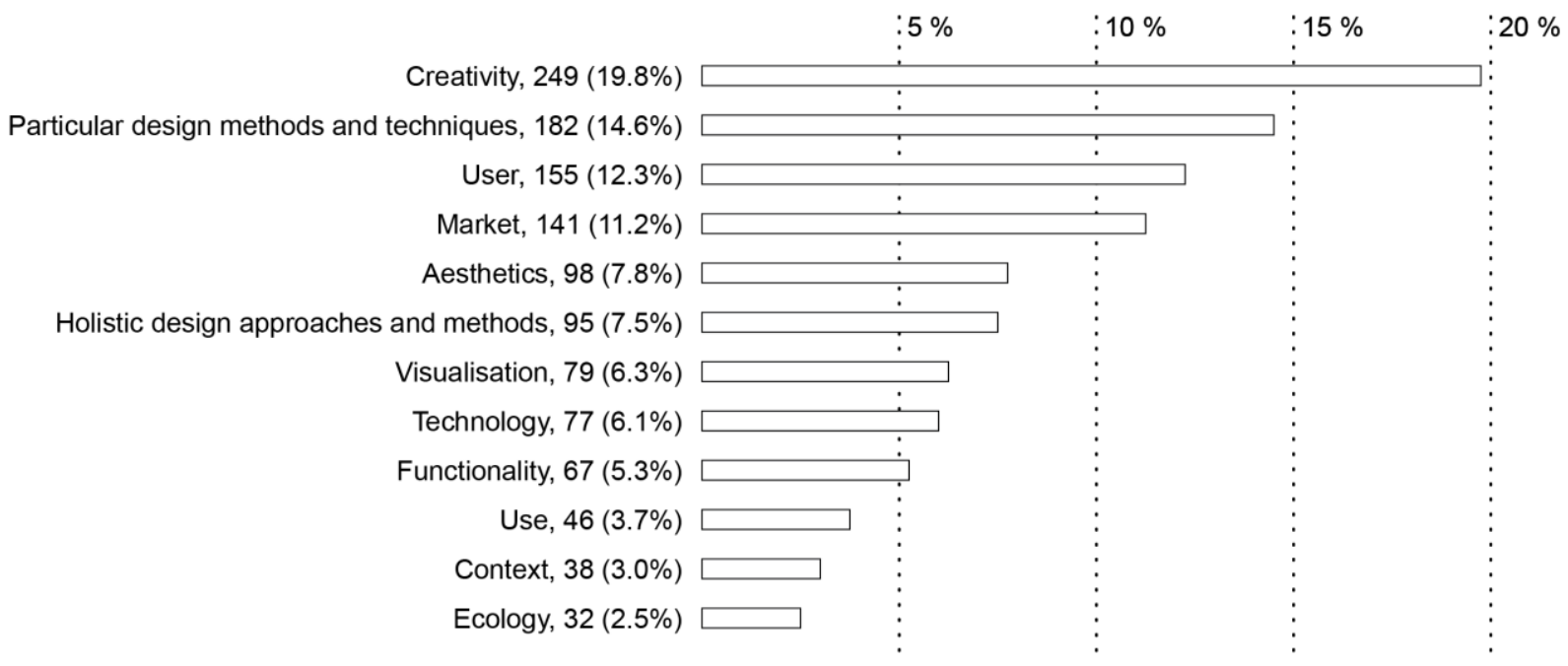

Fig. 1: Distribution of the pre-set list of 12 categories

In sum, 731 statements $(36.7 \%)$ were not captured by the categories. The application of Greenhouse-Geisser corrected repeated ANOVA post-hoc tests revealed that the residual competence category was significantly larger than every other category. This makes a strong case for carrying out a content analysis of the competence residual.

\section{Content analysis of competence residual}

The content analysis of the competence residual revealed two major categories: teamwork (386 statements or 19.4\%) and project management (130 statements or 6.5\%). Based on the content analysis results of the competence residual in the data, these could tentatively serve as categories 13 and 14 .

13) Teamwork. For a designer, team and teamwork issues arise in a designer in-group (designer to designer) and between a designer and client. Many models of teamwork exist in the literature, such as how teams develop over time (Tuckman, 1965), how they should be demographically composed (West, Hirst, Richter, \& Shipton, 2004), how they should be composed regarding personality (Hackman, 2002) and how to balance the types of models that describe which team functions must be present, regardless of who is actually performing these functions (Bales, Cohen, \& Williamson, 1979).

Most modern team theories consist of three main structures of functions: i) a task focus (sticking to the task at hand and not dwelling on less important issues), ii) a social focus (showing care and consideration for the members of the group) and iii) an opposition focus (systematic criticism of the ideas and processes that occur in the group) (Sjøvold, 2006).

14) Project management. The product management competence refers to work situations where the designer takes part in organising and structuring a project. A designer can have several roles in this organising activity.

The remaining residual now consists of 215 statements or $10.1 \%$ of the competence statements. Some of these border on tacit knowledge as a dimension, while others border on the design process; but as a whole, these are mainly personal reflections about particular matters and are difficult to grasp as clear-cut categories or competencies. These statements might refer to the expression of a category rather than a category of design core competence as such. However, we kept these statements as a residual for the remaining analyses. 


\section{A revised set of categories}

When collapsed into a single model, the taxonomy now accounts for 1,775 statements or $89.2 \%$ of the competence statements. The expanded list is distributed in descending order as follows (see Fig. 2): teamwork, 386 statements (21.7\%); creativity, 249 statements (14.0\%); particular design methods and techniques, 182 statements $(10.2 \%)$; user, 155 statements $(8.7 \%)$; market, 141 statements $(7.9 \%)$; project management, 130 statements (7.3); aesthetics, 98 statements (5.5\%); holistic design approaches and methods, 95 statements (5.4\%); visualisation, 79 statements (4.5\%); technology, 77 statements (4.3\%); functionality, 67 statements (3.8\%); use, 46 statements $(2.6 \%)$; context, 38 statements $(2.1 \%)$; and ecology, 32 statements $(1.8 \%)$

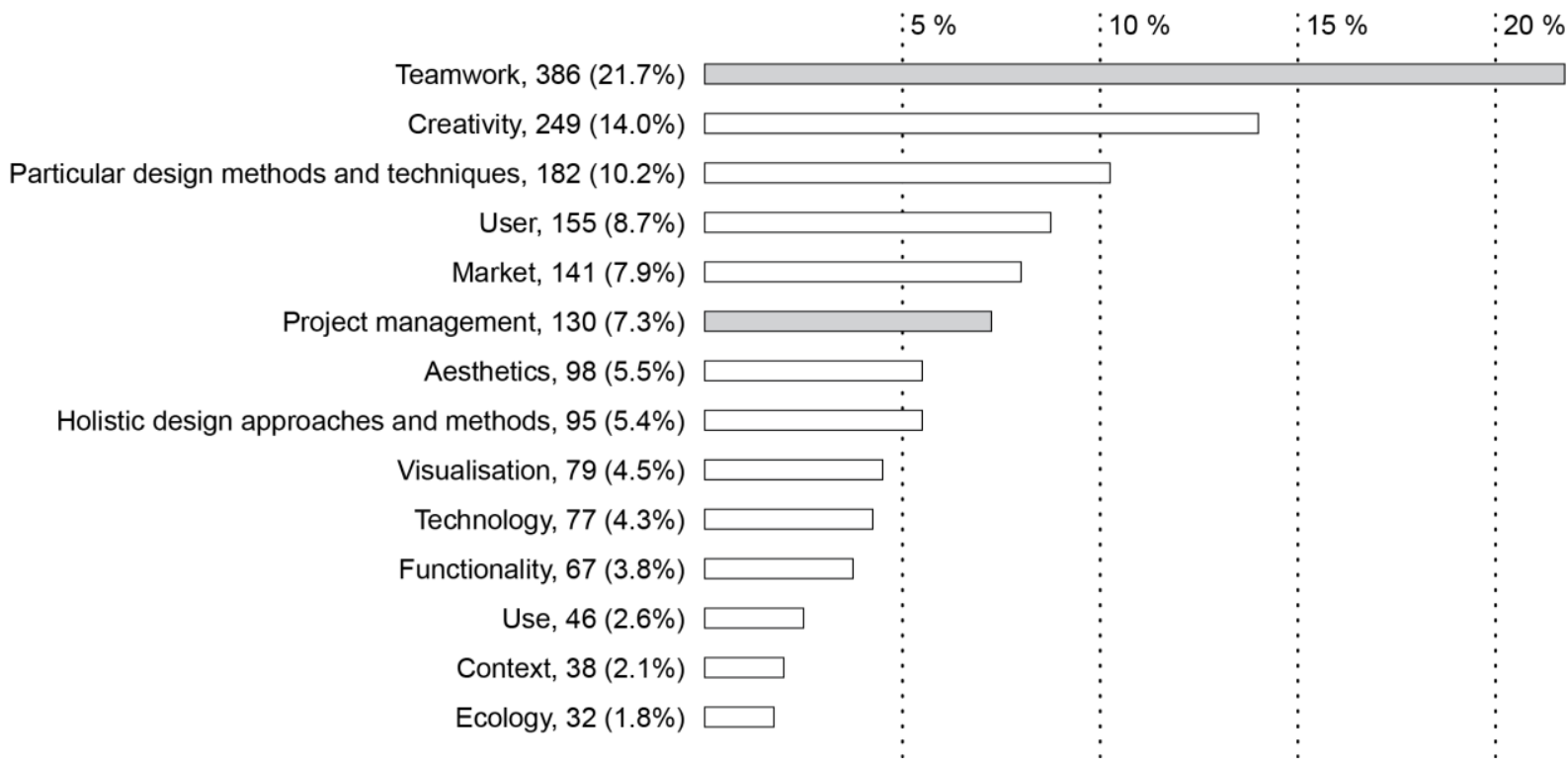

Fig. 2: Distribution of the expanded list of 14 categories

\section{Discussions}

As the pre-set categories were based partly on academic experience and partly on design curricula at the university level, we expected that the majority of statements would fit into these categories. Indeed, $63.3 \%$ of the interviewee statements matched the categories. There were no statistical differences between the separate categories. There was individual variation, thus contributing to non-significant differences between the dimensions. Descriptively, creativity accounted for a large proportion of the statements (19.8\%), whereas context and ecology accounted for a small proportion (each less than $4 \%$ ).

Based on the analysis of the statements, we conclude that the categorisation relates to what professional designers talk about when given the opportunity to reflect freely on their profession. However, because the statements were derived from professional industrial designers and not from academic researchers or students, we expected to find topics that did not match the initial twelve categories.

The residual of 731 statements, i.e., statements classified as a type of competence, but which did not fit into any of the initial dimensions, were then subjected to a bottom-up content analysis. Two dimensions did not match the categories: teamwork and project management. Teamwork accounted for a larger proportion of statements than any initial category. However, there were no statistical differences between the two new categories and the initial dimensions. Based on these data, we concluded that the competence residual 
provided additional information on what might constitute a taxonomy describing design core competencies.

\section{The revised categories}

Given the empirical and theoretical soundness of the two new categories, we combined them with the pre-set categories to form a new taxonomy. There were no statistical differences between the 14 categories (when using strict Bonferroni transformations), which means they are related to each other statistically. ${ }^{4}$ It is difficult to interpret the implications of the differences between the dimensions, as it is natural for different individuals within a discipline to have different types of professional competence. In fact, demonstrating differences between the dimensions might strengthen the suggested taxonomy.

A number of correlations between the dimensions revealed fascinating patterns. Functionality, aesthetics, use, context, technology, ecology, market and use seem to be candidates for core competencies, as they are significantly correlated with each other and can be viewed as 'core' categories.

\begin{tabular}{|c|c|c|c|c|c|c|c|c|c|c|c|c|c|c|c|c|}
\hline $\begin{array}{r}\text { Holistic design } \\
\text { approaches } \\
\text { and methods }\end{array}$ & 5.59 & 6374 & & & & & & & & & & & & & & \\
\hline Visualisation & 4.65 & 4743 & 0.309 & & & & & & & & & & & & & \\
\hline Aesthetics & 5.76 & 6722 & -0.274 & 0.140 & & & & & & & & & & & & \\
\hline Use & 2.71 & 3549 & -0.279 & 0.075 & $0.812^{\star *}$ & & & & & & & & & & & \\
\hline User & 9.12 & 9892 & -0.419 & -0.011 & 0.341 & $0.537^{*}$ & & & & & & & & & & \\
\hline Context & 2.24 & 3580 & -0.226 & 0.417 & 0.348 & 0.340 & 0.102 & & & & & & & & & \\
\hline Technology & 4.53 & 4432 & -0.273 & 0.411 & $0.523^{*}$ & 0.479 & 0.201 & $0.610^{\star *}$ & & & & & & & & \\
\hline Market & 8.29 & 8709 & -0.201 & -0.037 & $0.489^{*}$ & 0.242 & 0.245 & 0.090 & 0.033 & & & & & & & \\
\hline Ecology & 1.88 & 4314 & -0.116 & 0.367 & 0.383 & 0.471 & 0.280 & $0.710^{\star *}$ & $0.638^{* *}$ & 0.089 & & & & & & \\
\hline Functionality & 3.94 & 6932 & -0.259 & 0.476 & $0.562^{*}$ & $0.517^{*}$ & 0.184 & $0.718^{\star *}$ & $0.772^{\star *}$ & 0.270 & $0.877^{\star *}$ & & & & & \\
\hline Creativity & 14.59 & 17596 & 0.062 & 0.172 & 0.317 & 0.189 & 0.045 & 0.077 & 0.292 & $0.547^{*}$ & -0.010 & 0.160 & & & & \\
\hline Teamwork & 22.71 & 20282 & 0.007 & -0.273 & -0.245 & -0.250 & -0.164 & -0.346 & -0.223 & 0.103 & -0.295 & -0.239 & 0.151 & & & \\
\hline $\begin{array}{l}\text { Particular design } \\
\text { methods and } \\
\text { techniques }\end{array}$ & 10.71 & 8957 & -0.041 & -0.051 & 0.436 & 0.424 & 0.393 & -0.099 & 0.251 & 0.107 & 0.031 & -0.061 & 0.286 & -0.011 & & \\
\hline $\begin{array}{c}\text { Project } \\
\text { management }\end{array}$ & 7.59 & 9007 & -0.033 & 0.216 & 0.207 & -0.026 & -0.190 & 0.028 & 0.072 & $0.512^{*}$ & -0.043 & 0.089 & 0.057 & $0.499^{*}$ & 0.123 & \\
\hline Residual & 12.56 & 7632 & 0.227 & 0.027 & -0.013 & 0.086 & 0.083 & 0.292 & 0.126 & 0.077 & 0.120 & -0.044 & 0.040 & $0.489^{*}$ & $0.517^{*}$ & -0.029 \\
\hline
\end{tabular}

Fig. 3: Matrix of the correlations between the 14 categories

The two new categories, teamwork and project management, are significantly correlated with each other. However, they are significantly correlated with only one of the original dimensions, namely market. These dimensions are both externally oriented to customers, and make a strong case for a separate category that deals with issues of communication, trust, fulfilling the client's needs, ensuring that a project stays within its limits and so forth. Thus, this category might be conceived of as an external category.

The low correlation between visualisation and all the other dimensions is perhaps more difficult to explain. Visualisation is a 'particular design method or technique', but the two were negatively correlated, i.e., the more likely you are to talk about visualisation, the 
less likely you are to talk about other particular design methods or techniques. Visualisation might also be intuitively thought of as close to aesthetics, but they were also uncorrelated. Visualisation was negatively correlated to user (a plausible 'holistic' single category) and to the other external categories (team, project management and market). It is plausible that visualisation requires so many specific skills that the industrial designers who possess these skills need to downplay other competencies. In the same vein, it might be that professional designers with these skills are mainly used for this type of task, and not for other tasks such as those relating to external client-related issues. Thus, visualisation might constitute a particular "modelling" category.

Finally, holistic design approaches and methods and particular design methods and techniques were not at all correlated with the other dimensions. However, these two have a different nature from the other dimensions in that they describe a set of concrete procedures, i.e., the process of combining the different building blocks of categories supporting competence rather than the categories per se. This might make a case for treating these two dimensions differently or even excluding them from the taxonomy.

\section{Designer archetypes}

This discussion of categories begs the question of whether industrial designer archetypes exist. This question might be answered by a traditional qualitative grounded theory analysis of the data set. Based on the current data and our analysis, we suggest that one might construct analytical ideal types or nodes such as the following:
a) A traditional and more internal core designer who focuses mainly on functionality, aesthetics, use, context, technology, ecology, market and use
b) A more externally oriented designer, focusing mainly on teamwork and project management
c) A user-oriented designer, focusing mainly on use and user, adhering to user-centred design methods
d) A visualisation-oriented designer, focusing mainly on sophisticated 3D tools

Another relevant question is whether any categories should be removed from the taxonomy. The likely candidates are holistic design approaches and methods, particular design methods and techniques and ecology. As described above, in retrospect, the first two might be thought of more as processes rather than discrete categories describing core competencies of industrial design. The decision to possibly exclude these categories is supported by the fact that they are uncorrelated with any of the other categories. Regarding the list, we may also ask if ecology is related to competence, or is merely a topic of specific importance for designers. The small number of statements (32 out of 1,775) that concerned ecology could partly justify its exclusion. However, there were no statistical differences between ecology and the other categories in this data set. Furthermore, ecology was significantly correlated with several other categories. To conclude, we believe that the model would benefit from excluding the first two categories (holistic design approaches and methods and particular design methods and techniques), while ecology could remain, giving us a taxonomy comprising 12 categories.

\section{Conclusion}

The aim of this joint operation of building conversations with designers and mapping their common perceptions of design competencies was to pursue different means to better understand what designers actually talk about when they talk about design. Through empirical analysis, our approach was to test a set of categories that, in our experience, cover core competencies of industrial design. 
In the present study, we found some coherence between the design competence categories that were mainly based on design education curricula and what industrial designers talk about when they are encouraged to reflect freely on how they go about design work. Drawing on a residual analysis, we additionally revealed two notable exceptions representing two new categories. These categories contain issues related to teamwork and project management. One reason why these two were not listed among the first 12 categories might be an inherent inertia in our educational system revealing that we, at least on a formal level, have not adequately addressed recent changes in the design profession.

Today, it is not only the products that are more complex, but also the processes that facilitate the genesis of products. Thus, developing skills in teamwork and project management might be even more relevant in the future industrial design curricula. However, while working as an industrial designer, it might become harder, but perhaps also more necessary, to hold on to and develop a holistic approach to designing and knowing. Even though we have chosen to remove the holistic approach category from our taxonomy, it might represent a useful lens through which to analyse relevant trends and compare them to what we really would like to achieve. Some of our data might indirectly suggest that we are in fact moving away from a traditional holistic design approach toward a more specialised and particular approach. Is this a move enacted by design or merely by following the mainstream? In other words, what do we really want to achieve and how will we achieve it?

A comparable, but perhaps even more peculiar, result in the study is the low score of the category 'ecology'. Does this score imply that ecology should be removed from the curricula, or does it mean that it should be given even more emphasis? Should we adjust our curricula to the trends as we see them, or should we sometimes also counteract them? These questions could reveal new categories of future taxonomy, and could lead to being visionary versus merely refining the several kinds of industrial design curricula as we know them today.

To conclude this study, the proposed taxonomy constitutes an initial and tentative step toward a structural classification that makes comparisons of the reflections of professional designers and design clients clearer. A suggestion for further research is to interview novice design clients using a similar method and to classify the data according to a similar set of categories. The data could suggest where the discrepancies are between the designers' selfunderstanding of their competencies and design clients' knowledge of these competencies. With further knowledge in this area, and maybe a more accurate conception of eventual discrepancies, we might target client-designer communication more precisely, and thereby search for areas for strategic improvement of the design and product development processes. This is part of 'an ongoing conversation' between design professionals, interdisciplinary researchers, the application of mixed methods, the intersection of situated talk and taxonomic mappings, and ways of unpacking given and emerging knowledge about design competencies. We see these as cumulatively offering us rich means to continue to investigate what we talk about when we talk about design.

\section{Øivind Røise}

PhD student

The Oslo School of Architecture and Design, Institute of Design

Email address: Oivind.Roise@aho.no

\section{Håkan Edeholt}

Professor

The Oslo School of Architecture and Design, Institute of Design

Email address: Hakan.Edeholt@aho.no 
Øivind Røise, Håkan Edeholt, Andrew Morrison, Cato A. Bjørkli \& Thomas Hoff What We Talk About When We Talk About Design

\section{Andrew Morrison}

Professor

The Oslo School of Architecture and Design, Institute of Design

Email address: Andrew.Morrison@aho.no

\section{Cato A. Bjørkli}

Associate Professor

University of Oslo, Faculty of Social Sciences, Department of Psychology

Email address: C.A.Bjorkli@psykologi.uio.no

\section{Thomas Hoff}

Professor

University of Oslo, Faculty of Social Sciences, Department of Psychology

Email address: Thomas.Hoff@psykologi.uio.no 
Øivind Røise, Håkan Edeholt, Andrew Morrison, Cato A. Bjørkli \& Thomas Hoff What We Talk About When We Talk About Design

\section{References}

Argyris, C., \& Schön, D. A. (1974). Theory in practice: Increasing professional effectiveness. San Francisco: Jossey-Bass.

Bales, R. F., Cohen, S. P., \& Williamson, S. A. (1979). Symlog: A system for the multiple level observation of groups. New York: Free Press.

Bayazit, N. (2004). Investigating design: A review of forty years of design research. Design Issues, 20(1), 16-29. doi:10.1162/074793604772933739

Brown, T. (2009). Change by design: How design thinking transforms organizations and inspires innovation. New York, NY: Collins Business.

Buchanan, R. (1992). Wicked problems in design thinking. Design Issues, 8(2), 5-21.

Conley, C. (2004). Leveraging design's core competencies. Design Management Review, 15(3), 45-51.

Conley, C. (2011). The core competence of design. Retrieved from http://www.idsa.org/core-competenciesdesign

Cross, N. (1984). Developments in design methodology. Chichester: Wiley.

Cross, N. (2006). Designerly ways of knowing. London: Springer.

Cross, N. (2007). Forty years of design research. Design Studies, 28(1), 1-4.

Cross, N., Dorst, K., \& Christiaans, H. (1996). Analysing design activity. Chichester: Wiley.

Crouch, C., \& Pearce, J. (2012). Doing research in design. London: Berg.

Dorst, K., \& Cross, N. (2001). Creativity in the design process: Co-evolution of problem-solution. Design Studies, 22(5), 425-437. doi:10.1016/S0142-694X(01)00009-6

Flick, U. (2009). An introduction to qualitative research. Los Angeles: Sage.

Glaser, B., \& Strauss, A. L. (1967). The discovery of grounded theory: Strategies for qualitative research. Chicago: Aldine.

Grand, S., \& Jonas, W. (2012). Mapping design research. Basel: Birkhäuser.

Hackman, J. R. (2002). Leading teams: Setting the stage for great performances. Boston, MA: Harvard Business School Press.

Hatchuel, A., \& Weil, B. (1995). Experts in organizations: A knowledge-based perspective on organizational change. Berlin: Walter de Gruyter.

Hubka, V., \& Eder, W. E. (1990). Design knowledge: Theory in support of practice. Journal of Engineering Design, 1(1), 97-108. doi:10.1080/09544829008901646

Kimbell, L. (2011). Rethinking design thinking: Part I. Design and Culture, 3(3), 285-306.

Koskinen, I. (2011). Design research through practice: From the lab, field, and showroom. Waltham: Morgan Kaufmann.

Kvale, S., \& Brinkmann, S. (2009). Interviews: Learning the craft of qualitative research interviewing. Los Angeles, CA: Sage.

Latour, B. (2005). Reassembling the social: An introduction to actor-network-theory. Oxford: Oxford University Press.

Lawson, B. (1997). How designers think: The design process demystified. Oxford: Architectural Press.

Lawson, B. (2004). What designers know. Amsterdam: Elsevier.

Lawson, B., \& Dorst, K. (2009). Design expertise. Oxford: Architectural Press.

Lockwood, T. (2010). Design thinking: Integrating innovation, customer experience and brand value. New York: Allworth Press. 
Lone, J. A., Bjørklund, R. A., Østerud, K. B., Anderssen, L. A., Hoff, T., \& Bjørkli, C. A. (2013). Assessing knowledge-intensive work environment: General versus situation-specific instruments. European Journal of Work and Organizational Psychology, 1-14. doi:10.1080/1359432X.2012.750449

Löwgren, J., \& Stolterman, E. (2004). Thoughtful interaction design: A design perspective on information technology. Cambridge, MA: MIT Press.

McDonnell, J. (2012). Accommodating disagreement: A study of effective design collaboration. Design Studies, $33(1), 44-63$.

McDonnell, J., \& Lloyd, P. (2009). About designing: Analysing design meetings. Boca Raton, FL: CRC Press.

Moggridge, B., \& Atkinson, B. (2007). Designing interactions. Cambridge, MA: MIT Press.

Nelson, H. G., \& Stolterman, E. (2003). The design way: Intentional change in an unpredictable world: Foundations and fundamentals of design competence. Englewood Cliffs, NJ: Educational Technology Publications.

Oak, A. (2011). What can talk tell us about design? Analyzing conversation to understand practice. Design Studies, 32(3), 211-234.

Perneger, T. V. (1998). What's wrong with Bonferroni adjustments. British Medical Journal, 316(7139), 12361238.

Redström, J. (2006). Towards user design? On the shift from object to user as the subject of design. Design Studies, 27(2), 123-139.

Rittel, H. W. J., \& Webber, M. M. (1973). Dilemmas in a general theory of planning. Policy Sciences, 4(2), 155169.

Schön, D. A. (1983). The reflective practitioner: How professionals think in action. New York: Basic Books.

Simon, H. A. (1969). The sciences of the artificial. Cambridge, MA: The MIT Press.

Sjøvold, E. (2006). Teamet: Utvikling, effektivitet og endring i grupper (The team: Development, efficiency and change in groups). Oslo: Universitetsforl.

Strauss, A. L., \& Corbin, J. M. (1990). Basics of qualitative research: Grounded theory procedures and techniques. Newbury Park, CA: Sage.

Strauss, A. L., \& Corbin, J. M. (1997). Grounded theory in practice. Thousand Oaks, CA: Sage.

Thomas, G., \& James, D. (2006). Reinventing grounded theory: Some questions about theory, ground and discovery, British Educational Research Journal, 32(6), 767-795.

Tuckman, B. W. (1965). Developmental sequence in small groups. Psychological Bulletin, 63(6), 384-399. doi:10.1037/h0022100

Wagner, I., Stuedahl, D., \& Bratteteig, T. (2010). Exploring digital design: Multi-disciplinary design practices. London: Springer.

West, M. A., Hirst, G., Richter, A., \& Shipton, H. (2004). Twelve steps to heaven: Successfully managing change through developing innovative teams. European Journal of Work and Organizational Psychology, 13(2), 269-299. doi:10.1080/13594320444000092

\footnotetext{
${ }^{1}$ With a higher $n$, we would clearly get significant differences between the categories of the taxonomy. Even running an analysis of variance (ANOVA) without Bonferroni transformations makes about half of the differences between dimensions significant. The use of Bonferrroni transformations has been disputed (Perneger, 1998), but we applied them to be on the conservative side.

${ }^{2}$ There might be systematic differences between the two groups. For example, the 'external' category might have been dominated by statements made by experienced designers.

${ }^{3}$ We have shown in earlier studies that the inter-rater reliability is acceptable after about two hours of joint scoring. In this paper, we chose an approach in which inter-rater reliability was ensured by the process mentioned. In addition, we used two levels of quality control. First, a scientific assistant went through all statements to ensure they were scored according to the definitions. Second, a design professor went through the same procedure. In addition, some statements were difficult to interpret. In these cases, we went through entire sections of the transcriptions to ensure we captured the informants' meaning.
} 
Øivind Røise, Håkan Edeholt, Andrew Morrison, Cato A. Bjørkli \& Thomas Hoff What We Talk About When We Talk About Design

${ }^{4}$ This was mainly due to a combination of low $n$ and high standard deviations. Given a higher $n$ (even without using Bonferroni transformations), there would be a number of differences between the dimensions. 